\title{
BMJ Open Direct costs of osteoporosis-related hip fractures: protocol for a cross-sectional analysis of a national database
}

\author{
Zhila Maghbooli, ${ }^{1}$ Arash Hossein-nezhad, ${ }^{2}$ Maryam Jafarpour, ${ }^{3}$ Sima Noursaadat, ${ }^{3}$ \\ Majid Ramezani, ${ }^{1}$ Roxana Hashemian, ${ }^{4}$ Syamak Moattari ${ }^{5}$
}

To cite: Maghbooli Z, Hossein-nezhad A, Jafarpour M, etal. Direct costs of osteoporosisrelated hip fractures: protocol for a cross-sectional analysis of a national database. BMJ Open 2017;7:e014898. doi:10.1136/ bmjopen-2016-014898

- Prepublication history for this paper is available online. To view these files please visit the journal online (http://dx.doi. org/10.1136/bmjopen-2016014898).

Received 25 0ctober 2016 Revised 17 January 2017 Accepted 3 March 2017

\section{(a) CrossMark}

${ }^{1}$ Endocrinology and Metabolism Research Institute of Tehran University of Medical Sciences, Tehran, Iran

${ }^{2}$ Department of Medicine, Section of Endocrinology, Nutrition, and Diabetes, Vitamin D, Skin and Bone Research Laboratory, Boston University Medical Campus, Boston, Massachusetts, USA

${ }^{3}$ Statistics and Information Technology, Ministry of Health and Medical Education, Tehran, Iran

${ }^{4}$ Boston University School of Dental Medicine, Boston, Massachusetts, USA

${ }^{5}$ Department of Health Sciences, Worcester State University, Worcester, Massachusetts, USA

Correspondence to Dr Arash Hossein-nezhad; arash_hsi@yahoo.com

\section{ABSTRACT}

Introduction It is estimated that Iran accounted for about $1 \%$ of hip fracture burden of the world in 2007 , but these data are based on incomplete evidence. As the country's population is ageing, it is expected that a dramatic rise in hip fracture incidence will result. There is no single national study that accurately estimates the incidence of all hip fractures in the country or identifies the direct costs for affected patients. To help fill this gap, the current study has been designed to determine the incidence of hip fracture associated with osteoporosis in the Iranian population and to assess the direct costs involved.

Methods and analysis This is a cross-sectional analysis of 2 years of hospital admissions due to hip fracture in Iran from October 2014 to October 2016 using an electronic health record called SEPAS. SEPAS is a nationwide health information system established by Information Technology (IT) and the Statistics Department of the Ministry of Health SEPAS has recorded more than 8.5 million inpatient hospitalizations since October 2014. Our study will identify reported hip fracture data in SEPAS among admitted adult hospital patients aged $\geq 50$ in Iran. International Classification of Diseases ICD-9 and 10 will be used as diagnostic codes. Study factors are demographic data, types of fracture, types of treatment, duration of admission, early complications, in-hospital mortality and direct cost of fracture treatment. The accuracy of the SEPAS fracture data will be ascertained through a pilot study that compares the SEPAS data with the data directly extracted from medical records of the Shariati Hospital in Tehran during the study period.

Ethics and dissemination The study protocol was approved by the Ethics Committee of the National Institute for Medical Research Development of Iran. Dissemination plans include academic publications, conference presentations and social media.

\section{INTRODUCTION}

Observational studies on fracture incidence and their economic impact are necessary for public health assessment and for devising preventive strategies. Half of women and one-fifth of men after age 50 years are at risk of a fracture during their remaining lifetime. ${ }^{12}$ There are important consequences to patients who experienced a fracture such as morbidity, pain and decreased quality of life.

\section{Strengths and limitations of this study}

This study is the first nationwide data analysis of osteoporotic hip fractures in Iran, the different types of fractures and their direct economic costs using detailed medical records of SEPAS.

- By using the national identification number for each patient as a unique patient identifier in the current study, it is expected that the assessment of fracture incidence will be more accurate than previous studies.

- The accuracy of this national database for hip fracture was not previously tested, and in a concurrent pilot study designed as a part of this protocol, this accuracy will be evaluated.

- The study is based on inpatient data only. The data on outpatient hip fractures were not available for our national database analysis.

The cost of fractures is also remarkable. The healthcare cost of fracture is expected to increase twice by the year 2025 and the burden of fracture will be a significant public health problem. ${ }^{4-6}$

Estimation of osteoporotic fractures in the year 2000 indicated that approximately 9 million fractures have occurred worldwide, including 1.6 million hip fractures, 1.4 million symptomatic spine fractures and 1.7 million forearm fractures. ${ }^{2} 7$ These fractures are known as major osteoporotic fractures and accounted for noteworthy morbidity. Among them, hip and spine fractures are especially associated with excess mortality. ${ }^{28}$ By 2050 , due to the ageing population, hip fractures have been expected to rise to 6.26 million. ${ }^{9-12}$

Hip fracture is a thoughtful injury burden in the ageing population, ${ }^{13}$ with high mortality rates of $16 \%-23 \%$, during the first year after fracture. ${ }^{14-16}$ Incidence of hip fracture is widely assessed by using inpatient medical records as hospital admission is required for all hip fractures, a major contributor to the fact that hip fracture is among the most expensive orthopaedic procedures. ${ }^{13}$ 17-19 
Incidences of hip fracture have been evaluated in several studies in different countries in the world and results show a 10-fold variation in hip fracture incidence. ${ }^{10}$ This very large difference may be due to genetic variation in different ethnicities, different proportion of older residents, differences in lifestyles as well as different fracture registry methods on regional or national levels and in different calendar years. ${ }^{10}$ Economic costs are also highly sensitive to the healthcare environment. ${ }^{3}$ Thus, any healthcare cost assessment is typically country specific. ${ }^{320}$ It is also expected that the burden of osteoporotic fracture will differ among countries because of different incidence rates and a different proportion of an older population.

The ageing population is rapidly increasing in developing countries, and as a result it is expected that by 2050 most of hip fractures in the world (about $70 \%$ ) will occur in these countries. ${ }^{12} 21$ The high morbidity and mortality, loss of independence and healthcare cost highlight the necessity to monitor the incidence rate and related healthcare costs associated with these fractures. ${ }^{22-24}$ Because of this rising trend, these studies should be on the top priority list of public health assessment of developing countries. 3720

Considering the ageing trend of the Iranian population, the incidence of fracture is going to rise in the coming years. In the year 2010, there were an estimated 50000 hip fractures in Iran, and it is projected that this number will increase to 62000 by $2020 .^{25}$ A study of the burden of hip fracture in Iran in 2007 estimated that Iran accounted for about $1 \%$ of the hip fracture burden in the world and more than $12 \%$ of the burden in the Middle East. $^{21}$

Although earlier studies provide important information about the high prevalence of osteoporosis and osteopenia in Iran, some gaps in knowledge of the osteoporotic fractures remain. To help fill this gap, the proposed study has been designed to determine the incidence of a range of fractures of typical sites associated with osteoporosis and to assess the direct costs to Iranian population.

\section{Proposal questions}

The primary question of this nationwide data analysis is whether hip fracture is as prevalent as previously estimated and whether its direct costs are comparable to those of developed countries?

\section{Aims of this study}

The primary objective of the study is to estimate the national hip fracture incidence rate attributable to osteoporosis for the population recorded by SEPAS.

The secondary objectives are to calculate the direct costs due to hip fracture, and to determine the factors associated with elevated costs, types of fractures, types of treatments, duration of admission, early complications and in-hospital mortality in the population covered by the SEPAS.

\section{METHODS AND ANALYSIS}

\section{Study design}

This is a cross-sectional analysis of a nationwide database in Iran. The research has been supported by the National Institute for Medical Research Development of Iran (Grant No. 940 204).

\section{Data source}

Hospital discharge records will be analysed from SEPAS inpatient database from October 2014 to October 2016. SEPAS is a nationwide health information system established by Information Technology and the Statistics Department of the Ministry of Health. Based on our new pilot, more than 8.5 million inpatient hospitalizations have been registered by SEPAS since October 2014 .

\section{Study population}

Data will be included from fracture reports in SEPAS among admitted adult hospital patients aged $\geq 50$ from October 2014 to October 2016. Patients with a primary or secondary International Classification of Diseases, 9th and 10th revisions, Clinical Modification (ICD-9-CM and ICD-10-CM) diagnosis code indicating fracture of neck of femur (820.0-9, S.72.0-9), fracture of sacrum (S321), fracture of coccyx (S322), fracture of ilium (S323), fracture of acetabulum (S324) and fracture of pubis (S325), will be extracted from SEPAS. Most of these codes have been validated in the fragility fracture registry. ${ }^{26}$

Patients will be excluded if they are aged $<50$ years, or have any other injury with multiple trauma. Patients with pathologic fractures or patients with high-cost diseases such as cancer and chronic renal failure will be excluded to prevent the overestimation of medical costs. ${ }^{27} \mathrm{~A}$ flow chart of the study protocol is shown in figure 1.

\section{Study measurements}

Study factors that will be measured are demographic data, the incidence of fractures, types of fractures, types of treatments, duration of admission, early complications, in-hospital mortality and direct cost of fracture treatment.

Early complications evaluated in SEPAS include postoperative complications, which are the cause of reoperation and infection such as urinary tract infections, surgical site infections and pneumonia.

The lack of a unique patient identifier is a major disadvantage for hip fracture estimation. ${ }^{13} 28$ Thus, in the current nationwide analysis, the patient's national identification number will be used as a unique patient identifier.

The accuracy of the registered fracture admissions will be ascertained through a pilot study designed to compare the data from SEPAS with the data directly extracted from medical records of Shariati Hospital in Tehran.

\section{Cost of fractures}

Direct medical costs consist of the hospital (inpatient care), physicians, nurses, anaesthesia, laboratory, implant, operation that includes the overhead cost of fluoroscopy and surgical set, medications, and readmission. ${ }^{329}$ Costs of medicines will be determined based on the wholesale 


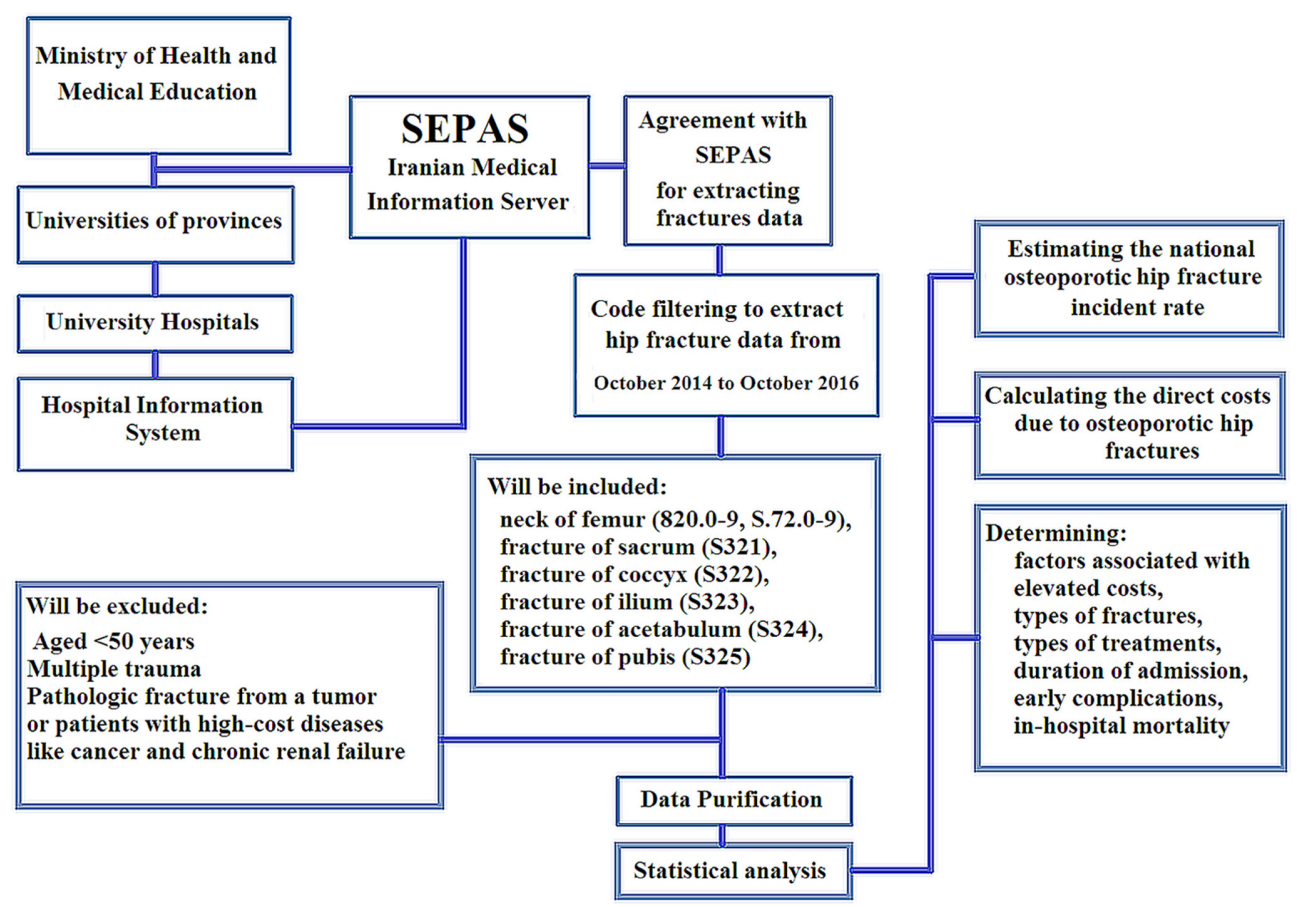

Figure 1 Flow chart of the study protocol. SEPAS is a nationwide health information system established by Information Technology and the Statistics Department of the Ministry of Health.

prices in 2015 that the pharmaceutical company offered to the Ministry of Health. The total expense of fracture treatment for each patient will be defined as unit fracture cost. It will be calculated by dividing the total expense by the number of patients. ${ }^{2} 29$

\section{Statistical analysis}

Patient characteristics will be shown as a percentage for categorical variables and for continuous variables by using the mean and SD. Student's t-test will be used for analyzing the mean difference of age, direct cost and duration of admission between two types of hip fractures (intra-capsular or extra-capsular), and Fisher's exact test will be used for percentage differences of early complications and in-hospital mortality rates between types of hip fractures. Costs will be calculated as direct medical costs. Each of the medical costs will be analysed as median and range. Significant $\mathrm{p}$ value will set equal to or less than 0.05 .

\section{DISCUSSION}

There is a very large discrepancy of hip fracture incidence in different provinces in Iran. The annual age-standardized incidence rates in Kermanshah were 181.1/100 000 in men and 214.6/100 000 in women. ${ }^{30}$ Age-standardized incidence rates for hip fracture in Shiraz were $329.57 / 100000$ in men and 1589.71/100 000 in women. ${ }^{31}$ The largest study concerning the epidemiology of hip fracture in Iran that was published in 2006 covered only nine provinces across the country in a period of 135 days. ${ }^{32}$ The current study protocol is the first nationwide data analysis of osteoporotic hip fractures in Iran. The data will be obtained from SEPAS, the largest scale health information system nationwide in Iran. All of the hospitals affiliated with 55 medical universities in all provinces, which provide services across the country, will be surveyed for any hip fractures occurring in the study period of 2 years. Thus, the current study protocol will present the largest epidemiological study of hip fracture in Iran. Another strength of current study is using patient's national identification number as a unique patient identifier. The lack of a unique patient identifier is a major issue in hip fracture estimation. ${ }^{132}$ The current study will also provide data analysis of different types of hip fractures, their treatments, their direct economic costs, duration of admission, early complications and in-hospital mortality using detailed medical records of SEPAS.

Previous study showed that burden of hip fracture in Iran is significant compared to all Middle Eastern countries, ${ }^{21}$ with high mortality rates of $24 \%$ during the first year after fracture. ${ }^{33}$ There is no detailed information about cost of hip fractures in Iran. Current protocol study has been designed to determine direct medical costs accompanied with hip fracture. This includes hospital (inpatient care), physicians, nurses, anaesthesia, laboratory, implant and operation (overhead cost of fluoroscopy and surgical set, medications, and readmission). These data will be collected for the first time in the country and would be helpful for strategic planning on hip fracture management in Iran. There are two limitations in this protocol. The first is related to the accuracy of fracture registry in SEPAS national database that has not been previously tested, and in a concurrent pilot study designed as a part of this protocol, this accuracy will be evaluated. The second is related to the outpatient data of hip fracture that were not available for our national database 
analysis. It is expected that the results of this study will directly improve the accuracy of SEPAS fracture registry.

\section{DISSEMINATION}

Dissemination plans include academic publications, conference presentations and social media. The results of this study will be communicated to the Ministry of Health and Medical Education via Center for Diseases Control and Non-Communicable Diseases Division and relevant organisations providing health services such as insurance companies. Results will also be disseminated to IT and the Statistics Department of the Ministry of Health to improve necessary procedures used to gather fracture registry records in SEPAS.

Contributors ZM, AH and MR conceived the study design. ZM, AH, SN, MJ, MR, RH and SM contributed to the design of data collection tools and wrote the statistical analysis plan. ZM, $\mathrm{AH}, \mathrm{SN}$ and $\mathrm{MJ}$ monitor the data collection and analysis of the data for the whole trial. ZM, AH, RH and SM drafted the manuscript, and all authors reviewed and revised the protocol. All authors approved the final protocol to be published.

Funding This work is supported by the National Institute for Medical Research Development of Iran (grant number IR.NIMAD.REC.940204).

Competing interests None declared.

Ethics approval The study protocol was approved by the Ethics Committee of the National Institute for Medical Research Development (NIMAD) of Iran.

Provenance and peer review Not commissioned; externally peer reviewed.

Open Access This is an Open Access article distributed in accordance with the Creative Commons Attribution Non Commercial (CC BY-NC 4.0) license, which permits others to distribute, remix, adapt, build upon this work non-commercially, and license their derivative works on different terms, provided the original work is properly cited and the use is non-commercial. See: http://creativecommons.org/ licenses/by-nc/4.0/

(c) Article author(s) (or their employer(s) unless otherwise stated in the text of the article) 2017. All rights reserved. No commercial use is permitted unless otherwise expressly granted.

\section{REFERENCES}

1. Johnell O, Kanis J. Epidemiology of osteoporotic fractures. Osteoporos Int 2005;16(Suppl 2):S3-S7.

2. Dimai HP, Redlich K, Peretz M, et al. Economic burden of osteoporotic fractures in Austria. Health Econ Rev 2012;2:12.

3. Leslie WD, Metge CJ, Azimaee M, et al. Direct costs of fractures in Canada and trends 1996-2006: a population-based cost-of-illness analysis. J Bone Miner Res 2011;26:2419-29.

4. van den Bergh JP, van Geel TA, Geusens PP. Osteoporosis, frailty and fracture: implications for case finding and therapy. Nat Rev Rheumatol 2012;8:163-72.

5. van Staa TP, Dennison EM, Leufkens HG, et al. Epidemiology of fractures in England and Wales. Bone 2001;29:517-22.

6. Kanis JA, Johnell O. Requirements for DXA for the management of osteoporosis in Europe. Osteoporos Int 2005;16:229-38.

7. Cooper C, Cole ZA, Holroyd CR, et al; IOF CSA Working Group on Fracture Epidemiology. Secular trends in the incidence of hip and other osteoporotic fractures. Osteoporos Int 2011;22:1277-88.

8. Johnell O, Kanis JA. An estimate of the worldwide prevalence and disability associated with osteoporotic fractures. Osteoporos Int 2006;17:1726-33.
9. Si L, Winzenberg TM, Jiang Q, et al. Projection of osteoporosisrelated fractures and costs in China: $2010-2050$. Osteoporos Int 2015;26:1929-37.

10. Dhanwal DK, Dennison EM, Harvey NC, et al. Epidemiology of hip fracture: Worldwide geographic variation. Indian J Orthop 2011;45:15-22.

11. Pitzul KB, Munce SE, Perrier L, et al. Quality indicators for hip fracture patients: a scoping review protocol. BMJ Open 2014;4:e006543.

12. Cooper C, Campion G, Melton LJ. Hip fractures in the elderly: a world-wide projection. Osteoporos Int 1992;2:285-9.

13. Vu T, Davie G, Barson D, et al. Accuracy of evidence-based criteria for identifying an incident hip fracture in the absence of the date of injury: a retrospective database study. BMJ Open 2013;3:e003222.

14. Wiktorowicz ME, Goeree R, Papaioannou A, et al. Economic implications of hip fracture: health service use, institutional care and cost in Canada. Osteoporos Int 2001;12:271-8.

15. De Laet CE, van Hout BA, Burger $\mathrm{H}$, et al. Incremental cost of medical care after hip fracture and first vertebral fracture: the Rotterdam study. Osteoporos Int 1999;10:66-72.

16. Berecki-Gisolf J, McClure R, Seubsman SA, et al; Thai Cohort Study team. Reporting of lifetime fractures: methodological considerations and results from the Thai cohort study. BMJ Open 2012;2:e001000.

17. Blomfeldt R, Törnkvist $\mathrm{H}$, Ponzer S, et al. Comparison of internal fixation with total hip replacement for displaced femoral neck fractures. Randomized, controlled trial performed at four years. $J$ Bone Joint Surg Am 2005;87:1680-8.

18. Blomfeldt R, Törnkvist H, Ponzer S, et al. Displaced femoral neck fracture: comparison of primary total hip replacement with secondary replacement after failed internal fixation: a 2-year follow-up of 84 patients. Acta Orthop 2006;77:638-43.

19. Boufous S, Finch C, Close J, et al. Hospital admissions following presentations to emergency departments for a fracture in older people. Inj Prev 2007;13:211-4.

20. Drummond MFS, Torrance MJ, O'Brien GW, et al. Methods for the economic evaluation of health care programs. New York: Oxford University Press, 2005.

21. Ahmadi-Abhari S, Moayyeri A, Abolhassani F. Burden of hip fracture in Iran. Calcif Tissue Int 2007;80:147-53.

22. Inacio MC, Weiss JM, Miric A, et al. A community-based hip fracture registry: population, methods, and outcomes. Perm J 2015;19:29-36

23. Abrahamsen B, van Staa T, Ariely R, et al. Excess mortality following hip fracture: a systematic epidemiological review. Osteoporos Int 2009;20:1633-50.

24. Papaioannou A, Wiktorowicz M, Adachi JD, et al. Mortality, independence in living, and re-fracture, one year following hip fracture in Canadians. Journal SOGC 2000;22:591-7.

25. Keshtkar A, Larijani B, Satleghi M, et al. The incidence of osteoporotic hip fracture in Iran, a review. Osteoporosis International 2010;21:S707-S07.

26. Torstensson M, Hansen AH, Leth-Møller K, et al. Danish registerbased study on the association between specific cardiovascular drugs and fragility fractures. BMJ Open 2015;5:e009522.

27. Kang HY, Park SE, Kang DR, et al. Estimating medical expenditure associated with osteoporotic hip fracture in elderly Korean women based on the national health insurance claims database 2002-2004. Value Health 2009;(12 Suppl 3):S93-S96.

28. Boufous $\mathrm{S}$, Finch $\mathrm{C}$. Estimating the incidence of hospitalized injurious falls: impact of varying case definitions. Inj Prev 2005;11:334-6.

29. Woratanarat $P$, Wajanavisit $W$, Lertbusayanukul $C$, et al. Cost analysis of osteoporotic hip fractures. J Med Assoc Thai 2005;88(Suppl 5):S96-104.

30. Beyranvand M, Mohammadi $\mathrm{G}$. Incidence of hip fracture in Kermanshah, Iran. Arch Osteoporos 2009;4(1-2):67-70.

31. Maharlouei N, Khodayari M, Forouzan F, et al. The incidence rate of hip fracture in Shiraz, Iran during 2008-2010. Arch Osteoporos 2014;9:165.

32. Moayyeri A, Soltani A, Larijani B, et al. Epidemiology of hip fracture in Iran: results from the Iranian multicenter study on accidental injuries. Osteoporos Int 2006;17:1252-7.

33. Seyedi HR, Mahdian M, Khosravi G, et al. Prediction of mortality in hip fracture patients: role of routine blood tests. Arch Bone Jt Surg $2015 ; 3: 51-5$ 